\title{
Ceftriaxone-associated pseudolithiasis in hemodialysis patients: a case series study
}

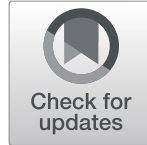

Yuko Oyama ${ }^{1 *}$, Yoichi Iwafuchi ${ }^{1}$ and Ichiei Narita ${ }^{2}$

\begin{abstract}
Background: Ceftriaxone, a third-generation cephalosporin, is widely used to treat bacterial infections in patients undergoing dialysis because it has a long half-life and broad spectrum of action and does not require dose reduction. However, renal dysfunction is a risk factor for ceftriaxone-associated pseudolithiasis that has rarely been reported in patients undergoing hemodialysis. This study aimed to present the detailed clinical manifestations of, and susceptibility to, ceftriaxone-associated pseudolithiasis in hemodialysis patients.

Methods: Seventy-seven hemodialysis patients received ceftriaxone between February 2011 and June 2019, and 33 patients underwent abdominal computed tomography within 1 year of receiving the drug. Among these 33 patients, 11 have developed ceftriaxone-associated pseudolithiasis. We retrospectively reviewed these patients' medical records. We also compared the medical records of ten patients who underwent computed tomography scans within 60 days of ceftriaxone administration and developed ceftriaxone-associated pseudolithiasis with those of patients who did not develop this adverse event.

Results: Pseudolithiasis tended to develop when patients received ceftriaxone for longer periods or at a higher total dosage. However, the ceftriaxone dose and the disease severity were not significantly correlated. Most patients improved within several months; however, the condition persisted for 10 months in a patient with a spinal cord injury. There were no significant differences in patient characteristics, prevalence of diabetes mellitus or cerebrovascular disease, being bed-bound, fasting, serum albumin, calcium, intact parathormone, or dose per unit body mass between the two groups. However, patients who developed pseudolithiasis had received ceftriaxone for significantly longer and at a higher total dose than those who did not develop pseudolithiasis (12 days; interquartile range $[\mathrm{IQ}], 8.3-14$ vs. 4 days, IQ, 2-8, $P=0.00872 ; 12.5 \mathrm{~g}, \mathrm{IQ}, 9.3-14$ vs. $4 \mathrm{~g}, \mathrm{IQ}, 2-8, P=0.00476$, respectively).

Conclusions: Ceftriaxone-associated pseudolithiasis may be relatively common in patients undergoing hemodialysis, especially in those who receive a higher total quantity of drug or for a longer duration. It is important to be aware of the possibility of pseudolithiasis developing in hemodialysis patients who receive ceftriaxone. These patients should be monitored during, and for up to 1 year after, its administration.
\end{abstract}

Keywords: Ceftriaxone, Pseudolithiasis, Hemodialysis

\footnotetext{
* Correspondence: oyamayuko@outlook.jp

'Department of Internal Medicine, Koseiren Sanjo General Hospital, 5-1-62,

Tsukanome, Sanjo 955-0055, Japan

Full list of author information is available at the end of the article
}

(C) The Author(s). 2021 Open Access This article is licensed under a Creative Commons Attribution 4.0 International License, which permits use, sharing, adaptation, distribution and reproduction in any medium or format, as long as you give appropriate credit to the original author(s) and the source, provide a link to the Creative Commons licence, and indicate if changes were made. The images or other third party material in this article are included in the article's Creative Commons licence, unless indicated otherwise in a credit line to the material. If material is not included in the article's Creative Commons licence and your intended use is not permitted by statutory regulation or exceeds the permitted use, you will need to obtain permission directly from the copyright holder. To view a copy of this licence, visit http://creativecommons.org/licenses/by/4.0/ The Creative Commons Public Domain Dedication waiver (http://creativecommons.org/publicdomain/zero/1.0/) applies to the data made available in this article, unless otherwise stated in a credit line to the data. 


\section{Background}

Ceftriaxone is a third-generation cephalosporin that is widely used for the treatment of bacterial infections because of its long half-life and broad spectrum of action $[1,2]$. The kidneys eliminate $45-60 \%$ of the infused ceftriaxone, and the remainder is excreted in the bile; therefore, dose reduction is not required, even in patients with renal dysfunction unless they also have liver dysfunction [3]. Thus, ceftriaxone is often used in dialysis patients who have bacterial infections [4]. The adverse effect of ceftriaxone-associated pseudolithiasis is frequently reported in children but rarely in adults. Although renal failure is a risk factor for ceftriaxoneinduced pseudolithiasis, there are few comprehensive reports on its frequency or details about its clinical course when using this drug in hemodialysis patients. In this retrospective study, we report 11 cases of ceftriaxoneassociated pseudolithiasis in hemodialysis patients. We also compared the medical records of patients with or without pseudolithiasis who underwent computed tomography scans within 60 days of ceftriaxone administration.

\section{Methods}

Seventy-seven hemodialysis patients who had received ceftriaxone at the Department of Internal Medicine, Koseiren Sanjo General Hospital, between February 2011 and June 2019 were reviewed sequentially. Among them, 11 patients with pre-existing biliary lithiasis and two who had a cholecystectomy were excluded from this study. CT had been performed to follow-up at the infection site or to investigate abdominal symptoms and/or liver dysfunction or another episode of infection.

Ceftriaxone-associated pseudolithiasis was diagnosed following the identification of new biliary stones or sludge by CT after initiating drug administration.

In previous studies $[5,6]$, the observation period was 60 days. However, in some cases, pseudolithiasis took 5 months to 1 year to resolve [7]. Therefore, we also investigated patients who were screened by CT within 60 days to 1 year after initiating treatment with ceftriaxone.

Clinical and laboratory findings for patients with ceftriaxone-associated pseudolithiasis were obtained from their medical records and included the age, sex, duration of dialysis, body mass, body mass index, type of primary renal dysfunction, site of infection, history of cerebrovascular disease (CVD), fasting status, bed rest status, administration of calcium-containing drugs, and laboratory data, such as the serum albumin, albuminadjusted calcium, and intact parathormone (int-PTH) levels. Abdominal symptoms and signs of liver dysfunction were recorded, as well as the dose and duration of ceftriaxone, the interval in days between the development of pseudolithiasis and the initiation of ceftriaxone, and the interval in days between cessation of the drug and resolution of pseudolithiasis.

We then compared the medical records of ten patients who underwent computed tomography scans within 60 days of ceftriaxone administration and developed ceftriaxone-associated pseudolithiasis with those of other patients who did not develop pseudolithiasis. In patients with repeated ceftriaxone administration, we analyzed the initial duration and total dose of the drug, which may contribute to pseudolithiasis development.

\section{Statistical analysis}

Continuous data are expressed as the mean \pm standard deviation or the median and interquartile range. Categorical data were compared using chi-square or Fisher's exact test. Continuous variables were compared using an independent $t$ test or the Mann-Whitney $U$ test. Data analyses were performed using EZR (Saitama Medical Center, Jichi Medical University, Saitama, Japan) [8]. $P<$ 0.05 was considered to indicate a statistical significance.

\section{Results}

CT was used to screen 24 patients within 60 days of initiating ceftriaxone, and 11 of the 24 patients were diagnosed with ceftriaxone-associated pseudolithiasis. One of these patients did not wish to provide informed consent and was excluded from the study. Data from nine patients who were screened by CT between 60 days and 1 year after initiating the drug were also recorded. Pseudolithiasis was diagnosed in one of these patients, and this patient was also included in this study. The patient selection process that was used in this case series is shown in Fig. 1.

Eleven patients were diagnosed with ceftriaxoneassociated pseudolithiasis among the 33 patients who underwent CT within 1 year of ceftriaxone administration and recruitment into this study. These patients' baseline characteristics are shown in Table 1.

The durations for which patients underwent dialysis upon initiation of ceftriaxone treatment varied widely (Table 1). Patients 3 and 7 started receiving ceftriaxone 1 and 2 days, respectively, before initiating hemodialysis, and patient 10 started ceftriaxone and hemodialysis simultaneously. Five patients were underweight (body mass index $\left.<18.5 \mathrm{~kg} / \mathrm{m}^{2}\right)$, two were obese $\left(>23 \mathrm{~kg} / \mathrm{m}^{2}\right)$, and four were within the normal range. Five patients (45.4\%) had diabetes mellitus (DM) as their primary disease, and this was effectively controlled by dietary therapy (patients 2, 3, and 6), an oral antidiabetic agent (patient 9), or insulin (patient 4).

The lungs were the predominant site of infection. Five patients (45.4\%) had a history of CVD. All patients had a low risk of aspiration and were therefore not instructed to fast; none were emaciated or malnourished. Seven patients 


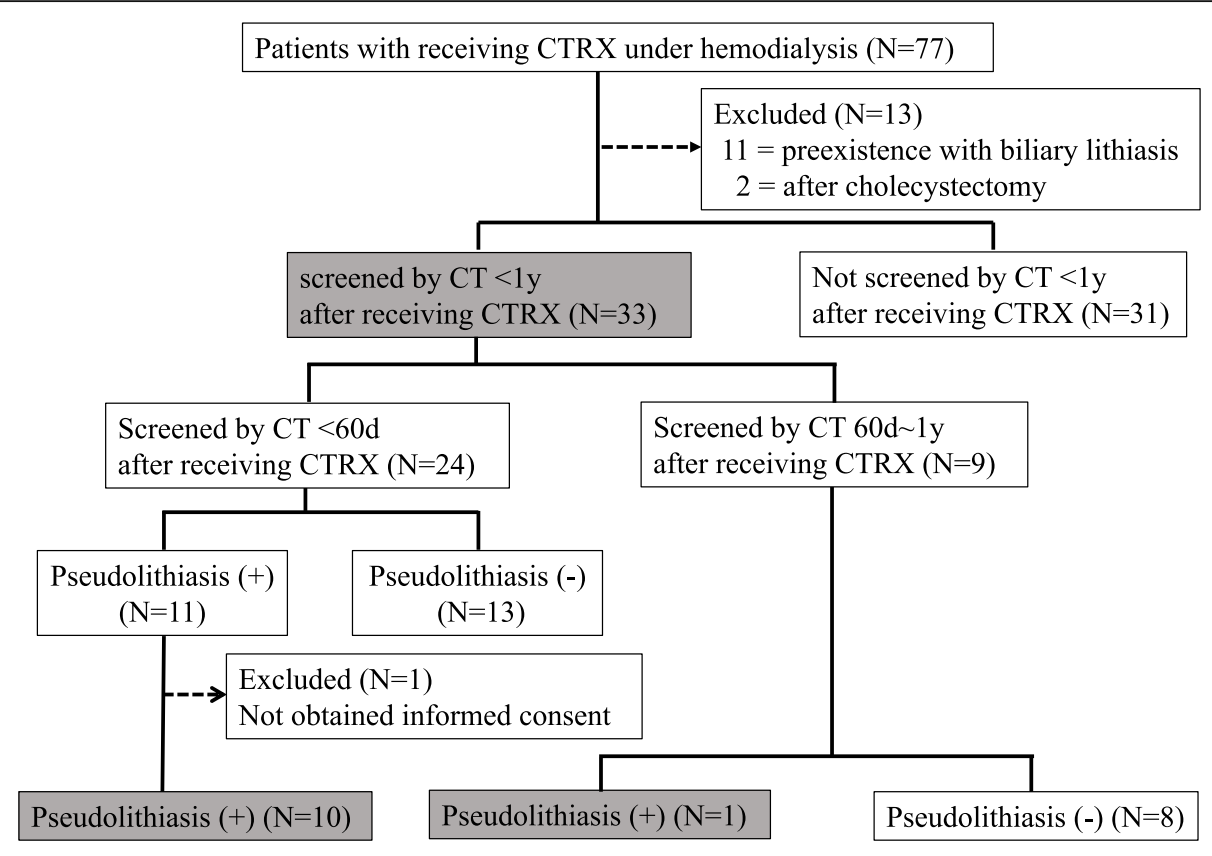

Fig. 1 Patient selection process

were bed-bound. Calcium-containing drugs were administered to two patients, but none received calciumcontaining infusions. Ten patients (90.9\%) were hypoalbuminemic $(<3.5 \mathrm{~g} / \mathrm{dL})$, and no patient presented with hypercalcemia or severe secondary hyperparathyroidism.

The clinical characteristics of the 11 patients with ceftriaxone-associated pseudolithiasis are shown in Table
2. Three of these patients (patients 1, 10, and 11) did not have abdominal symptoms or abnormalities in their transaminase or biliary enzyme levels, but two (patients 6 and 8) had both findings and were diagnosed as having cholecystitis. Patient 9 had a history of taking a low dose of ceftriaxone for a short period on another occasion $(1 \mathrm{~g}$ for 3 days) but did not develop pseudolithiasis at that time.

Table 1 Baseline characteristics of the patients with pseudolithiasis

\begin{tabular}{|c|c|c|c|c|c|c|c|c|c|c|c|c|}
\hline Patient & Age/sex & $\begin{array}{l}\text { Duration of dialysis } \\
\text { after starting } \\
\text { ceftriaxone (days) }\end{array}$ & BMI & $\begin{array}{c}\text { Primary } \\
\text { disease/ } \\
\text { comorbidity }\end{array}$ & $\begin{array}{l}\text { Infection } \\
\text { site }\end{array}$ & CVD & Fasting & $\begin{array}{l}\text { Bed- } \\
\text { bound }\end{array}$ & $\begin{array}{l}\text { Ca-containing } \\
\text { drug }\end{array}$ & $\begin{array}{l}\text { Serum } \\
\text { Alb } \\
\text { (g/dL) }\end{array}$ & $\begin{array}{l}\text { Adjusted } \\
\text { serum } \\
\text { Ca } \\
\text { (mg/dL) }\end{array}$ & $\begin{array}{l}\text { Int-PTH } \\
\text { (pg/mL) }\end{array}$ \\
\hline 1 & $85 / F$ & 1170 & 14.7 & MPA & Lung & - & - & + & - & 1.4 & 10.4 & 48 \\
\hline 2 & $82 / M$ & 1215 & 18.9 & DM & Unknown & + & - & - & + & 3.0 & 8.8 & 87 \\
\hline 3 & $83 / F$ & $-1^{\mathrm{a}}$ & 20.6 & DM & Lung & + & - & + & - & 2.7 & 8.8 & 365 \\
\hline 4 & $71 / F$ & 2469 & 26.7 & DM & Lung & + & - & + & - & 3.4 & 10.7 & 163 \\
\hline 5 & $68 / M$ & 20 & 18.4 & SLE & Lung & - & - & + & - & 1.8 & 9.6 & 81 \\
\hline 6 & $83 / \mathrm{M}$ & 928 & 18.1 & DM & Lung & + & - & + & + & 3.0 & 9.5 & 132 \\
\hline 7 & $65 / M$ & $-2^{a}$ & 27.9 & IRGN & $\begin{array}{l}\text { Lung, } \\
\text { penile } \\
\text { abscess }\end{array}$ & - & - & - & - & 2.0 & 9.7 & - \\
\hline 8 & $85 / M$ & 8 & 16.2 & $\begin{array}{l}\text { Unknown/ } \\
\mathrm{CO}_{2} \text { narcosis }\end{array}$ & Lung & - & - & + & - & 3.1 & 8.9 & 252 \\
\hline 9 & $32 / F$ & 868 & 17.6 & FSGS & Lung & - & - & - & - & 3.5 & 9.5 & 113 \\
\hline 10 & $82 / M$ & 0 & 19.6 & DM & Lung & + & - & - & - & 3.7 & 9.1 & 69 \\
\hline 11 & 70/M & 1065 & 20.2 & $\begin{array}{l}\text { CGN/spinal } \\
\text { cord injury }\end{array}$ & Lung & - & - & + & - & 2.8 & 8.8 & 116 \\
\hline
\end{tabular}

Alb Albumin, BMI Body mass index, Ca Calcium, CGN Chronic glomerulonephritis, CVD Cerebrovascular disease, DM Diabetes mellitus, FSGS Focal segmental glomerulonephritis, Int-PTH Intact parathormone, IRGN Infection-related glomerulonephritis, SLE Systemic lupus erythematosus, MPA Microscopic polyangiitis, M Male, $F$ Female

${ }^{a}$ Patients 3 and 7 started receiving ceftriaxone 1 and 2 days, respectively, before initiation of hemodialysis; thus, these numbers are shown as negative 
Table 2 Clinical characteristics of the patients with pseudolithiasis

\begin{tabular}{|c|c|c|c|c|c|c|c|c|}
\hline Patient & $\begin{array}{l}\text { Abdominal } \\
\text { symptoms }\end{array}$ & $\begin{array}{c}\text { Abnormalities in levels of } \\
\text { transaminases/biliary } \\
\text { enzymes }\end{array}$ & $\begin{array}{l}\text { Dose of CTRX [g/ } \\
\text { day } \times \text { duration } \\
\text { (days)] }\end{array}$ & $\begin{array}{l}\text { Dose of CTRX } \\
(\mathrm{mg} / \mathrm{kg} / \text { day })\end{array}$ & $\begin{array}{c}\text { a Days to } \\
\text { development }\end{array}$ & $\begin{array}{c}\text { bDays to } \\
\text { disappearance }\end{array}$ & Site & Treatment \\
\hline 1 & - & $-/-$ & $2 \times 13$ & 60.6 & 15 & $-^{c}$ & GB & - \\
\hline 2 & - & $+/-$ & $1 \times 14$ & 21.5 & 27 & 319 & GB & - \\
\hline 3 & Vomiting & $+/-$ & $1 \times 14$ & 21.6 & 35 & 78 & GB & Fasting \\
\hline 4 & Nausea & $-/+$ & $1 \times 14$ & 16.0 & 36 & 117 & GB & Antibiotics \\
\hline 5 & - & $+/-$ & $\begin{array}{c}1 \times 9(1 \times 8,1 \times 5,1 \\
\times 11)\end{array}$ & 17.9 & 25 & 168 & GB & Antibiotics \\
\hline 6 & $\begin{array}{l}\text { Appetite } \\
\text { loss }\end{array}$ & $+/+$ & $1 \times 14$ & 21.0 & 14 & $-{ }^{c}$ & GB & $\begin{array}{l}\text { Fasting, } \\
\text { antibiotics }\end{array}$ \\
\hline 7 & Vomiting & $-/-$ & $2 \times 2,1 \times 6$ & 13.1 & 19 & 20 & GB & $\begin{array}{l}\text { Fasting, } \\
\text { UDCA }\end{array}$ \\
\hline 8 & Epigastralgia & $+/+$ & $1 \times 11(1 \times 14)$ & 27.4 & 43 & 50 & $\begin{array}{l}\mathrm{GB} \\
\mathrm{CBD}\end{array}$ & $\begin{array}{l}\text { UDCA, } \\
\text { antibiotics }\end{array}$ \\
\hline 9 & Epigastralgia & $-1-$ & $1 \times 8(1 \times 3)$ & 22.7 & 21 & 37 & GB & UDCA \\
\hline 10 & - & $-/-$ & $1 \times 7$ & 18.7 & 8 & 39 & $\mathrm{~GB}$ & - \\
\hline 11 & - & $-/-$ & $1 \times 4$ & 17.5 & 274 & 424 & GB & - \\
\hline
\end{tabular}

CTRX Ceftriaxone, CBD Common bile duct, GB Gall bladder, UDCA Ursodeoxycholic acid

${ }^{\mathrm{a}}$ From the initiation of CTRX

${ }^{b}$ From the cessation of CTRX

'These patients died before their follow-up abdominal CT

Patient 5 received ceftriaxone several times $(1 \mathrm{~g}$ for $5-11$ days) within a few months because of repeated uncontrolled infection and because he was allergic to other antibiotics except for ceftriaxone, but he showed no clinical features of cholecystitis. Although patient 1 received a relatively high dose of ceftriaxone ( $2 \mathrm{~g}$ for 13 days) and exhibited a high level of biliary sludge (Fig. 2a), she was asymptomatic. Patient 8 was re-administered ceftriaxone for a longer period (11 vs. 14 days) and had a pseudolithiasis relapse; however, the second episode was less severe, with no abdominal symptoms or increases in biliary enzyme concentrations. Thus, there was no clear correlation between the dose of ceftriaxone that was administered and the severity of pseudolithiasis. Abdominal symptoms developed after cessation of ceftriaxone administration in all patients who were diagnosed with ceftriaxone-

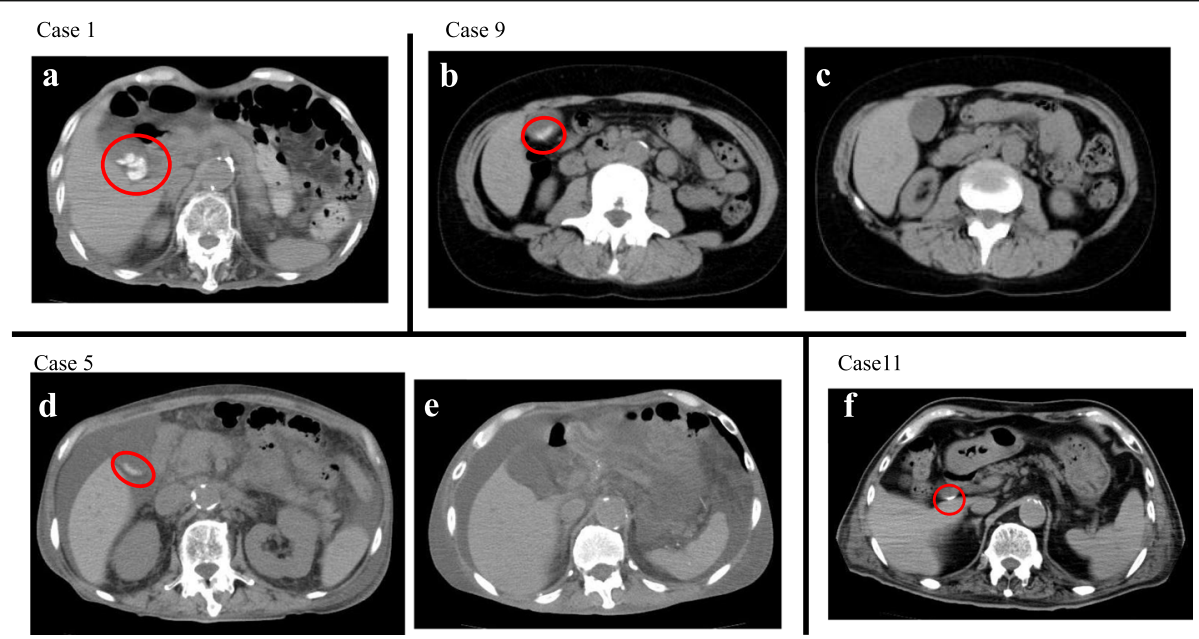

Fig. 2 Abdominal computed tomography images for each patient. a (Patient 1): A large high-density lesion appeared in the gall bladder 15 days after ceftriaxone administration. b, c (Patient 9): A high-density lesion appeared in the gall bladder 21 days after administration of ceftriaxone (b), and it had completely resolved 37 days after cessation of ceftriaxone (c). d, e (Patient 5): A small high-density lesion appeared in the gall bladder 25 days after administration of ceftriaxone (d), and it had finally resolved 168 days after cessation of the first course of ceftriaxone (e). $\mathbf{f}$ (Patient 11): A high-density lesion was still present 274 days ceftriaxone administration in patient 11 who had a spinal cord injury 
associated pseudolithiasis. Only one patient (patient 10) was screened prospectively for pseudolithiasis despite a lack of abdominal symptoms; he was recognized as having pseudolithiasis within the ceftriaxone administration period, and ceftriaxone was discontinued soon afterward. Pseudolithiasis was diagnosed several days to months after the initiation of ceftriaxone and resolved several months after its cessation in most instances (Fig. 2b, c). The condition took a relatively long time to resolve in patient 5 , who had pseudolithiasis after repeated administration of ceftriaxone (Fig. 2d, e). For patients 2 and 11, CT was performed a relatively long time after ceftriaxone administration when the next episode of infection occurred. Pseudolithiasis was present 274 days after the initiation of ceftriaxone in patient 11, who had a spinal cord injury (Fig. 2f). Symptomatic patients were treated by fasting or administration of antibiotics and/or ursodeoxycholic acid, and none required an invasive endoscopic or surgical procedure. Ceftriaxone-associated pseudolithiasis resolved spontaneously in all affected patients, except patients 1 and 6, who died before their follow-up abdominal CT.

\section{Comparison of clinical characteristics in patients with or without pseudolithiasis}

Among 13 patients who underwent CT scans $<60$ days after ceftriaxone administration and did not develop pseudolithiasis, two patients did not wish to provide informed consent, and they were excluded from the study. The remaining 11 patients without pseudolithiasis were enrolled into the study (Fig. 3). Table 3 shows the clinical characteristics and dosage/duration of ceftriaxone that was administered to patients with and without pseudolithiasis. There were no significant differences in patient characteristics, the prevalence of $\mathrm{DM}$ or CVD, being bed-bound, fasting, or serum albumin, calcium, or int-PTH between the two groups. There was also no significant difference in the dose per unit body mass, but there was a significant difference in the duration and total dose of ceftriaxone that was administered between the two groups.

\section{Discussion}

In the present study, we retrospectively investigated 11 patients who underwent hemodialysis and developed ceftriaxone-associated pseudolithiasis. The baseline characteristics varied among the patients; hypoalbuminemia was present in 10 of them, but none had severe malnutrition.

There was no clear relationship between the dose of ceftriaxone that was administered and the severity of pseudolithiasis. In most patients, the pseudolithiasis resolved within several months of ceftriaxone discontinuation, but one patient with a spinal cord injury still had pseudolithiasis approximately 10 months later, despite taking a relatively low dose.

The development of pseudolithiasis was significantly associated with the duration and total ceftriaxone dose that was administered.

Ceftriaxone is a widely used third-generation parenteral cephalosporin that has broad-spectrum antibacterial activity against Gram-positive and Gram-negative bacteria [2]. Its advantages include good tissue penetration and a long elimination half-life that permits oncedaily administration [1]. Approximately half of the ceftriaxone that is administered is eliminated by the kidney (45-60\%), and the remainder is excreted in the bile. In addition, ceftriaxone binds strongly to albumin and is not removed from the plasma by hemodialysis [4]. Generally, dose adjustment is not required for patients with renal dysfunction, unless they also have liver dysfunction or take doses exceeding $2 \mathrm{~g} /$ day [3]. Thus, ceftriaxone is widely used in patients with end-stage renal failure who develop a range of infections, including respiratory, urinary tract and soft tissue infections, and meningitis, and its use is rarely associated with adverse effects [4].

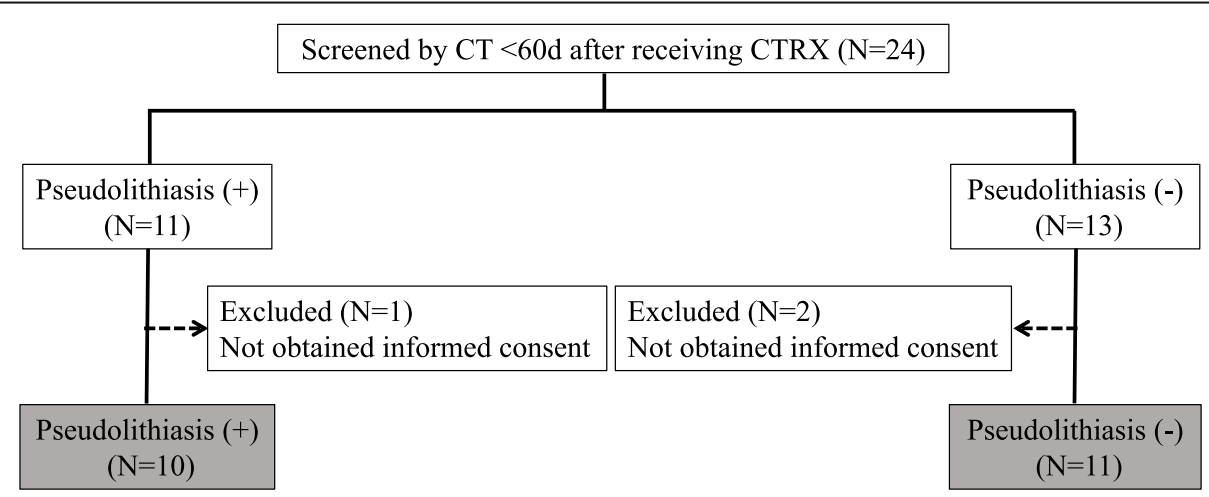

Fig. 3 Flow chart for analysis of with/without developing pseudolithiasis 
Table 3 Comparison between patients with and without pseudolithiasis

\begin{tabular}{|c|c|c|c|}
\hline & Pseudolithiasis $(n=10)$ & No pseudolithiasis $(n=11)$ & $P$ value \\
\hline Age (years) & $73.9 \pm 16.5$ & $71.1 \pm 18.7$ & 0.72 \\
\hline Male sex, $n(\%)$ & $6(63.6)$ & $7(61.9)$ & 0.86 \\
\hline $\mathrm{DM}, \mathrm{n}(\%)$ & $5(50.0)$ & $2(18.2)$ & 0.12 \\
\hline CVD, $n(\%)$ & $5(50.0)$ & $4(36.4)$ & 0.53 \\
\hline Body mass (kg) & $50.1 \pm 12.5$ & $52.4 \pm 9.0$ & 0.64 \\
\hline Body mass index $\left(\mathrm{kg} / \mathrm{m}^{2}\right)$ & $19.9 \pm 4.3$ & $20.9 \pm 2.8$ & 0.53 \\
\hline Ca-containing drug, $n(\%)$ & $2(20.0)$ & $3(27.3)$ & 0.70 \\
\hline Bed-bound, $n(\%)$ & $6(60.0)$ & $4(36.4)$ & 0.28 \\
\hline Fasting, $n(\%)$ & $0(0)$ & $1(15.4)$ & 0.33 \\
\hline \multicolumn{4}{|l|}{ Laboratory } \\
\hline Albumin (g/dL) & $2.8 \pm 0.8$ & $3.0 \pm 0.6$ & 0.35 \\
\hline Calcium (mg/dL) & $9.5 \pm 0.6$ & $9.4 \pm 0.6$ & 0.75 \\
\hline Int-PTH (pg/mL) & $113.0(81.0-163.0)$ & $143.0(94.0-228.0)$ & 0.61 \\
\hline Dose of CTRX (mg/kg/day) & $21.3(18.1-22.4)$ & $17.2(16.1-19.8)$ & 0.17 \\
\hline Duration of CTRX infusion (day) & $12(8.3-14)$ & $4(2-8)$ & $0.00872^{*}$ \\
\hline Total dose of CTRX (g) & $12.5(9.3-14)$ & $4(2-8)$ & $0.00476^{*}$ \\
\hline
\end{tabular}

DM Diabetes mellitus, CVD Cerebrovascular disease, Ca Calcium, Int-PTH Intact parathormone, CTRX Ceftriaxone

*Statistically significant $(P<0.05)$

The first pediatric case of ceftriaxone-associated pseudolithiasis was reported by Schaad et al. in 1986 [9]. Since then, many pediatric cases but few adult cases have been reported [10]. The prevalence has been shown to be $14-46.5 \%$ in children [5], but only $0-19 \%$ are symptomatic $[11,12]$, meaning that this adverse effect may be overlooked. The mechanisms of ceftriaxoneassociated pseudolithiasis have been described and are discussed below. Because $40 \%$ of infused ceftriaxone is excreted in the bile, it is present in the gall bladder (GB) at 20-150 times the concentration found in the serum. Because of its high concentration in the GB and its high binding affinity for calcium ions, ceftriaxone precipitates as an insoluble calcium salt in the GB, forming biliary sludge or stones. This is referred to as "pseudolithiasis" because of the spontaneous reversibility of the ultrasonographic findings and the relief that is obtained from abdominal symptoms after cessation of ceftriaxone administration [5]. Pseudolithiasis appears 4-7 days after initiation of ceftriaxone and resolves 2-63 days after its discontinuation [5]. Most (85-90\%) of the infused ceftriaxone binds to albumin in the blood, and the remaining ceftriaxone is excreted unchanged by the GB and kidney. Thus, hypoalbuminemia and renal dysfunction are risk factors for pseudolithiasis.

Other risk factors for pseudolithiasis include fasting, being bed-bound, and dehydration, all of which cause cholestasis by preventing GB contraction. These risk factors are consistent with those of common cholelithiasis, and they contribute to ceftriaxone accumulation in the GB. They also include hypercalcemia, high ceftriaxone dosage $(>2 \mathrm{~g} /$ day [13] or $>100 \mathrm{mg} / \mathrm{kg} /$ day [14]), and/or long duration of treatment. UDPglucosyltransferase family 1 member A1 (UGT1A1) gene polymorphisms were recently proposed to be another possible risk factor [15].

Although renal dysfunction is considered a risk factor, this contention is based on only a few case reports $[16,17]$.

There have been few comprehensive studies of the prevalence or biology of pseudolithiasis. Recently, Imafuku et al. reported that female sex and renal dysfunction, but not hemodialysis (prevalence of 5.4\%, hazard ratio 1.81), were independent risk factors [18]. However, another retrospective cohort study showed that hemodialysis and the dose of ceftriaxone were the main risk factors (prevalence of 9.7\%) [19]. Thus, no consensus has been reached on its prevalence or risk factors in hemodialysis patients.

In the present study, among the 33 patients who underwent abdominal computed tomography within 1 year of receiving the drug, 11 patients had ceftriaxoneassociated pseudolithiasis, which suggests that there is a relatively high incidence among hemodialysis patients.

Taking ceftriaxone for a short period did not lead to the development of pseudolithiasis. However, its repeated administration caused prolonged pseudolithiasis. Most patients received ceftriaxone at a dose of $1 \mathrm{~g} /$ day.

In previous studies in pediatric patients $[5,6]$, the observational period was 60 days, and there has been little 
research on pseudolithiasis beyond 60 days [20]. Additionally, there have been no prospective studies about the time course for developing pseudolithiasis after ceftriaxone administration in hemodialysis patients. Silent cases of pseudolithiasis that are presented in this report are consistent with the results of previous studies [11]. Therefore, it is uncertain whether pseudolithiasis had occurred without symptoms and had already resolved even in non-incident patients who underwent CT scans after 60 days of treatment with ceftriaxone. Thus, we compared patients with or without pseudolithiasis who underwent $\mathrm{CT}$ scans within 60 days after ceftriaxone administration.

Most of these patients had hypoalbuminemia, which may synergistically increase biliary excretion with renal dysfunction, although there was no significant difference in patients with or without pseudolithiasis.

The development of pseudolithiasis was significantly associated with the duration and total dose of ceftriaxone that was administered.

Thus, consistent with previous reports, pseudolithiasis development was associated with the duration and total dosage of ceftriaxone that was administered, but our study differed because the dose did not exceed $2 \mathrm{~g}$ /day. This could be explained because ceftriaxone may accumulate in hemodialysis patients who take it for a longer duration because its elimination half-life is much longer in patients with renal dysfunction $(11.7-17.3 \mathrm{~h}$ vs. $6-8.5$ $h$ in the absence of renal dysfunction) $[3,4]$.

We did not find a relationship between the dose of ceftriaxone that was administered and the severity of pseudolithiasis. It is possible that another factor, which may be genetic or environmental, is involved in the development of pseudolithiasis or determines the severity of the disease. Further studies are needed to investigate these factors.

In previous studies, pseudolithiasis was found up to 63 days [5] but not after 6 months [20] after initiation of ceftriaxone. However, in some patients, 5 months to 1 year was required for pseudolithiasis to resolve [7]. Thus, we decided to set the observation period to both within 60 days and from 60 days to 1 year after initiating ceftriaxone treatment. We found that pseudolithiasis persisted for 10 months in one patient with a spinal cord injury. It was recently reported that pseudolithiasis may not necessarily always be directly caused by high doses of ceftriaxone, but rather by fasting or being bed-bound, which are conditions that are associated with GB dysmotility. This may increase the concentration and decrease the excretion of ceftriaxone, which result in drug accumulation in the GB [21]. Therefore, the long duration of pseudolithiasis in the patient with a spinal cord injury might be due to the associated GB dysmotility.
There were several limitations to this study. Because we could not obtain CT images for all patients who had received ceftriaxone and because the times at which these CT scans were performed varied among the patients, we could not identify the exact timing of the development or resolution of pseudolithiasis or its prevalence. We also could not identify predictors of pseudolithiasis development or severity because our study population was small and did not include a control group. Further study and publication of similar cases are needed.

\section{Conclusions}

Ceftriaxone-associated pseudolithiasis may be relatively common in patients undergoing hemodialysis, particularly those who receive the drug for a longer duration and at a larger total dosage. It is important to be aware of this adverse effect and to carefully monitor patients for several months to 1 year after the ceftriaxone administration, especially patients who may also have GB dysmotility.

\section{Abbreviations}

Alb: Albumin; BMl: Body mass index; Ca: Calcium; CBD: Common bile duct; CGN: Chronic glomerulonephritis; CT: Computed tomography;

CTRX: Ceftriaxone; CVD: Cerebrovascular disease; DM: Diabetes mellitus; FSGS: Focal segmental glomerulonephritis; GB: Gall bladder; int-PTH: Intact parathormone; IRGN: Infection-related glomerulonephritis; MPA: Microscopic polyangiitis; SLE: Systemic lupus erythematosus; UDCA: Ursodeoxycholic acid

\section{Acknowledgements}

We thank Natasha Beeton-Kempen, PhD, from Edanz Group (https://enauthor-services.edanz.com/ac) for editing a draft of this manuscript.

\section{Authors' contributions}

YO designed the study and wrote the manuscript. YI contributed to the concept and helped write the manuscript. IN supervised the study. All authors read and approved the final manuscript.

Funding

Not applicable.

\section{Availability of data and materials}

The datasets used and/or analyzed during the current study are available from the corresponding author on reasonable request.

\section{Ethics approval and consent to participate}

All procedures involving human participants were conducted in accordance with the ethical standards of the institutional research committee at the Koseiren Sanjo General Hospital (IRB approval number 201910) and with the 1964 Declaration of Helsinki and its later amendments. Written informed consent was obtained from all patients or from their relatives where the patients had died before the study.

\section{Consent for publication}

Not applicable.

\section{Competing interests}

The authors declare that they have no competing interests.

\section{Author details}

'Department of Internal Medicine, Koseiren Sanjo General Hospital, 5-1-62, Tsukanome, Sanjo 955-0055, Japan. ²Division of Clinical Nephrology and Rheumatology, Niigata University Graduate School of Medical and Dental Sciences, 1-757 Asahimachi-dori, Chuo-ku, Niigata 951-8120, Japan. 
Received: 2 October 2020 Accepted: 4 January 2021

Published online: 05 February 2021

\section{References}

1. Patel IH, Chen S, Parsonnet M, Hackman MR, Brooks MA, Konikoff J, Kaplan SA. Pharmacokinetics of ceftriaxone in humans. Antimicrob Agents Chemother. 1981;20:634-41.

2. Cleeland R, Squires E. Antimicrobial activity of ceftriaxone: a review. Am J Med. 1984;77:3-11.

3. Patel IH, Sugihara JG, Weinfeld RE, Wong EG, Siemsen AW, Berman SJ. Ceftriaxone pharmacokinetics in patients with various degrees of renal impairment. Antimicrob Agents Chemother. 1984;25:438-42.

4. Cohen D, Appel GB, Scully B, Neu HC. Pharmacokinetics of ceftriaxone in patients with renal failure and in those undergoing hemodialysis. Antimicrob Agents Chemother. 1983;24:529-32.

5. Schaad UB, Wedgwood-Krucko J, Tschaeppeler H. Reversible ceftriaxoneassociated biliary pseudolithiasis in children. Lancet. 1988;2:1411-3.

6. Palanduz A, Yalcin I, Tonguc E, Guler N, Ones U, Salman N, Somer A. Sonographic assessment of ceftriaxone-associated biliary pseudolithiasis in children. J Clin Ultrasound. 2000;28:166-8.

7. Bonnet JP, Abid L, Dabhar A, Levy A, Soulier Y, Blangy S. Early biliary pseudolithiasis during ceftriaxone therapy for acute pyelonephritis in children: a prospective study in 34 children. Eur J Pediatr Surg. 2000;10:368-71.

8. Kanda Y. Investigation of the freely available easy-to-use software 'EZR' for medical statistics. Bone Marrow Transplant. 2013;48:452-8.

9. Schaad UB, Tschappeler H, Lentze MJ. Transient formation of precipitations in the gallbladder associated with ceftriaxone therapy. Pediatr Infect Dis. 1986;5:708-10.

10. Bickford CL, Spencer AP. Biliary sludge and hyperbilirubinemia associated with ceftriaxone in an adult: case report and review of the literature. Pharmacotherapy. 2005;25:1389-95.

11. Schaad UB, Suter S, Gianella-Borradori A, Pfenninger J, Auckenthaler R, Bernath $\mathrm{O}$, Cheseaux JJ, Wedgwood J. A comparison of ceftriaxone and cefuroxime for the treatment of bacterial meningitis in children. N Engl J Med. 1990;322:141-7.

12. Papadopoulou F, Efremidis S, Karyda S, Badouraki M, Karatza E, Panteliadis C, Malaka K. Incidence of ceftriaxone-associated gallbladder pseudolithiasis. Acta Paediatr. 1999;88:1352-5.

13. Shiffman ML, Keith FB, Moore EW. Pathogenesis of ceftriaxone-associated biliary sludge. In vitro studies of calcium-ceftriaxone binding and solubility. Gastroenterology. 1990;99:1772-8.

14. Biner B, Oner N, Celtik C, Bostancioglu M, Tuncbilek N, Guzel A, Karasalihoglu S. Ceftriaxone-associated biliary pseudolithiasis in children. J Clin Ultrasound. 2006;34:217-22.

15. Fretzayas A, Liapi O, Papadopoulou A, Nicolaidou P, Stamoulakatou A. Is Ceftriaxone-induced biliary pseudolithiasis influenced by UDPglucuronosyltransferase 1A1 gene polymorphisms? Case Rep Med. 2011; 2011:730250.

16. Abe S. A case of ceftriaxone-associated biliary pseudolithiasis in an elderly patient with renal dysfunction. IDCases. 2017;9:62-4.

17. Shima A, Suehiro T, Takii M, Soeda H, Hirakawa M. Reversible ceftriaxoneinduced pseudolithiasis in an adult patient with maintenance hemodialysis. Case Rep Nephrol Dial. 2015;5:187-91.

18. Imafuku A, Sawa N, Sekine A, Kawada M, Hiramatsu R, Yamanouchi M, Hasegawa E, Hayami N, Hoshino J, Ubara Y, Takaichi K. Risk factors of ceftriaxone-associated biliary pseudolithiasis in adults: influence of renal dysfunction. Clin Exp Nephrol. 2018;22:613-9.

19. Ubukata M, Ohsawa I, Suzuki H, Asao R, Nakamura Y, Nishida H, Nakamura M, Nitta K, Goto Y, Gotoh H. Hemodialysis as a risk factor for ceftriaxoneassociated pseudolithiasis in adults. Ther Apher Dial. 2019. https://doi.org/ 10.1111/1744-9987.13445.

20. Cometta A, Gallot-Lavallee-Villars S, Iten A, Cantoni L, Anderegg A, Gonvers $\mathrm{JJ}$, Glauser MP. Incidence of gallbladder lithiasis after ceftriaxone treatment. J Antimicrob Chemother. 1990;25:689-95.

21. Murata S, Aomatsu T, Yoden A, Tamai H. Fasting and bed rest, even for a relatively short period, are risk factors for ceftriaxone-associated pseudolitiasis. Pediatr Int. 2015;57:942-6.

\section{Publisher's Note}

Springer Nature remains neutral with regard to jurisdictional claims in published maps and institutional affiliations.

Ready to submit your research? Choose BMC and benefit from:

- fast, convenient online submission

- thorough peer review by experienced researchers in your field

- rapid publication on acceptance

- support for research data, including large and complex data types

- gold Open Access which fosters wider collaboration and increased citations

- maximum visibility for your research: over $100 \mathrm{M}$ website views per year

At BMC, research is always in progress.

Learn more biomedcentral.com/submissions 